NBER WORKING PAPER SERIES

\title{
STRUCTURAL TRANSFORMATION AND THE DETERIORATION OF EUROPEAN LABOR MARKET OUTCOMES
}

\author{
Richard Rogerson \\ Working Paper 12889 \\ http://www.nber.org/papers/w12889 \\ NATIONAL BUREAU OF ECONOMIC RESEARCH \\ 1050 Massachusetts Avenue \\ Cambridge, MA 02138 \\ February 2007
}

I have benefitted from the comments of numerous seminar participants. I am particularly grateful to Daron Acemoglu, Tassos Adamopoulos, Patrick Kehoe, Ellen McGrattan, and Victor Rios-Rull for comments, to Aspen Gorry for research assistance, and to the NSF for financial support. The views expressed herein are those of the author(s) and do not necessarily reflect the views of the National Bureau of Economic Research.

(C) 2007 by Richard Rogerson. All rights reserved. Short sections of text, not to exceed two paragraphs, may be quoted without explicit permission provided that full credit, including $\odot$ notice, is given to the source. 
Structural Transformation and the Deterioration of European Labor Market Outcomes

Richard Rogerson

NBER Working Paper No. 12889

February 2007

JEL No. E2,J2

\begin{abstract}
$\underline{\text { ABSTRACT }}$
This paper examines the evolution of hours worked in France, Germany, Italy and the US from 1956-2003 and assesses the role of taxes and technology to account for the differences. The empirical work establishes three results. First, hours worked in Europe decline by almost $45 \%$ compared to the US over this period. This change is almost an order of magnitude larger than the effects associated with the increase in unemployment over this time period. Second, the decline occurs at a steady pace from 1956 until the mid 1990s, in contrast to the fact that the relative increase in unemployment occurs in the mid 1970s. Third, the decline in hours worked in Europe is almost entirely accounted for by the fact that Europe develops a much smaller service sector than the US. I build a simple model of time allocation to understand the evolution of total hours worked and their distribution across sectors, and calibrate it to match the US between 1956 and 2000. I find that relative increases in taxes and technological catch-up can account for most of the differences between the European and American time allocations over this period.
\end{abstract}

Richard Rogerson

Department of Economics

College of Business

Arizona State University

Tempe, AZ 85287

and NBER

richard.rogerson@asu.edu 


\section{Introduction}

Beginning in the early to mid 1970's the economies of continental Europe experienced a sharp and persistent increase in unemployment rates relative to the US. This observation has motivated a large literature that seeks to understand the reason for the deterioration in European labor market outcomes. ${ }^{1}$ A common approach has been to look for common shocks that occurred in the 1970s and institutional differences that led to different propagation of those shocks.

While the unemployment rate is often used to measure aggregate labor market outcomes, an obvious alternative, in the tradition of Lucas and Rapping (1969), is to focus on hours of market work. The first contribution of this paper is to provide an analysis of changes in market work in Europe and the US over the period 1956-2003. Two key findings emerge. First, although outcomes in Europe deteriorate relative to the US whether measured in terms of unemployment or hours of work, the timing of the changes is very different. Whereas differences in unemployment rates emerge in the mid 1970's, the decline in hours of market work in Europe relative to the US begins in the mid 1950s and continues at a fairly steady rate until the mid 1990's. In particular, neither the time series for absolute or relative hours of market work in Europe displays any apparent change in behavior in the 1970s relative to either the 1960s or the 1980s. Second, the decrease in relative hours of work is much larger, by roughly an order of magnitude. Hours of work in France, Italy and Germany decline by more than $45 \%$ relative to the US, while the change in hours of work associated with the relative increase in unemployment is only about $4 \%$. Two conclusions emerge from this analysis. First, even if we understood the causes of the different evolutions in unemployment, there are dramatic differences in the evolution of hours of work that would remain unaccounted for. Second, focusing only on the period since 1970 is likely to be misleading since the relative decline in hours of work begins much earlier.

The second contribution of the paper is to show that a defining property of the evolution of hours of work in Europe relative to the US is that European economies have not developed a market service sector similar to that in the US as they have caught up to the US in terms of overall development. In particular, I argue that one must view the evolution of sectoral labor allocations in the US and Europe from the perspective of the structural transformation of economic activity that accompanies the process of development. Poor economies devote most of their resources to agriculture, but as they develop, activity moves first from agricultural to manufacturing and services, and then later from both manufacturing and agriculture into services. In the mid 1950s Europe lags the US in terms of development, but closes much of the gap during the subsequent 45 years. Accordingly, one expects that relative to the US, in the mid 1950s

\footnotetext{
${ }^{1}$ Examples include Bertola and Ichino (1996), Daveri and Tabellini (1997), Ljungqvist and Sargent (1998), Mortensen and Pissarides (1999a), Blanchard and Wolfers (2000), den Haan, Haefke and Ramey (2002), and den Haan (2003).
} 
Europe should have a much higher employment rate in agriculture and industry, and much lower in services. This conjecture is confirmed by the data. Since Europe has effectively caught up to the US by 2000, as measured by output per hour, holding all else constant one would expect that sectoral labor allocations look similar in Europe and the US. However, as of 2000, Europe has largely converged to the US levels for employment rates in agriculture and industry, but employment in services is only $70 \%$ of the level in the US, which is the same as it was in 1956. In 2000 almost all of the difference in hours of work are accounted for by differences in the service sector.

Having established these facts, I develop a simple model of time allocation across activities, calibrate it to match the US structural transformation over the period 19562000, and use this model to account for Europe's hours of work relative to the US in 1956 and 2000. Given that the changes occur at a fairly steady pace over a long period, it seems natural to consider driving forces that also exhibit ongoing change over the period 1956-2000. My analysis focuses on two such candidates: differences in the size of government tax and spending programs, and differences in technology. Two main results are obtained. First, differences in aggregate hours of work in 1956 and their distribution across sectors can largely be accounted for by the fact that Europe lags the US technologically by about 40 years. In particular, the model accounts for the fact that hours of work in 1956 are almost ten percent higher in Europe despite the fact that tax rates are higher. Second, differences in hours of work in 2000 and their distribution across sectors can largely be accounted for by the fact that Europe has tax rates on the order of $15-20 \%$ higher than the US.

Combined, these two findings tell us that it is the combination of relative changes in technology and taxes that account for the different evolution of both total market work, and its distribution across sectors. Specifically, the reason that Europe fails to develop a service sector similar to the US is that at the same time that changing technology creates an economic force leading to greater hours of work in the service sector, Europe raises taxes, thus creating an opposing force that encourages services to be provided outside of the market. A key feature of the model is that individuals are able to produce good substitutes for many market services using a home production technology, thus explaining why higher taxes thus cause the production of services to move from the market sector to the home sector, and the asymmetric effect of taxes across sectors. This mechanism is similar to the marketization of production view stressed by Freeman and Schettkat (2002) and supported by their analysis of time use studies for Germany and the US. Time use studies by Olovsson (2004), and Ragan (2005) also support this mechanism, as does the analysis of Davis and Henrekson (2004) based on more aggregate data. 2

\footnotetext{
${ }^{2}$ Messina (2003) argues that entry barriers in the service sector may also have been quantitatively important in affecting the movement of labor into the market service sector in Europe. See also Fonseca, Lopez-Garcia and Pissarides (2001) for empirical evidence in support of this effect in a cross-section of countries and Bertrand and Kramarz (2002) for the analysis of a specific entry barrier in France.
} 
An outline of the paper follows. Section 2 contrasts the behavior of unemployment and hours of work differences in Europe and the US over the period 1956-2003. Section 3 shows how the different evolution of aggregate hours of work is dominated by the differences in the evolution in the market service sector along the process of structural transformation. Section 4 presents a model of structural transformation, which is calibrated in Section 5 and then used to account for European hours of work in Section 6 . Section 7 concludes.

\section{Aggregate Labor Market Outcomes in Europe and the US}

While there is a large literature contrasting the evolution of aggregate labor market outcomes between the US and continental Europe, the bulk of this literature uses the aggregate unemployment rate as its reference measure for aggregate labor market outcomes. This section demonstrates that one obtains a very different perspective on the evolution of differences in aggregate labor market outcome if one instead focuses on the amount of work being done.

I contrast average outcomes in France, Germany and Italy with those in the US, and will refer to the average of France, Germany and Italy as corresponding to Europe. Similar results emerge with a larger set of countries from the continent chosen to represent Europe, but I focus on these three for two reasons. First, they are the three largest economies in continental Europe and second, these three (along with Belgium) are currently the European economies with the lowest levels of hours worked.

\subsection{Data}

The labor market data used here is obtained from two sources. Annual data on employment, unemployment and population comes from the OECD Employment Database. Data on annual hours of work per person in employment comes from the Groningen Growth and Development Center. Data is available going back to 1956, so the period considered is 1956-2003. Total hours of work is measured as the product of employment and annual hours of work per person in employment. To make comparisons across time and countries, one needs to normalize aggregate hours of work by some measure of population. I choose the size of the population aged 15-64 (referred to as the working age population) as the normalizing factor. Because our interest is in the low frequency changes in the data, attention is focused on trend components, which are defined using the HP filter with a smoothing parameter of 100 .

\subsection{Hours Worked in the US and Europe}

This subsection contrasts the evolutions of aggregate hours worked in Europe and the US. Figure 2.1 shows the trend components. 


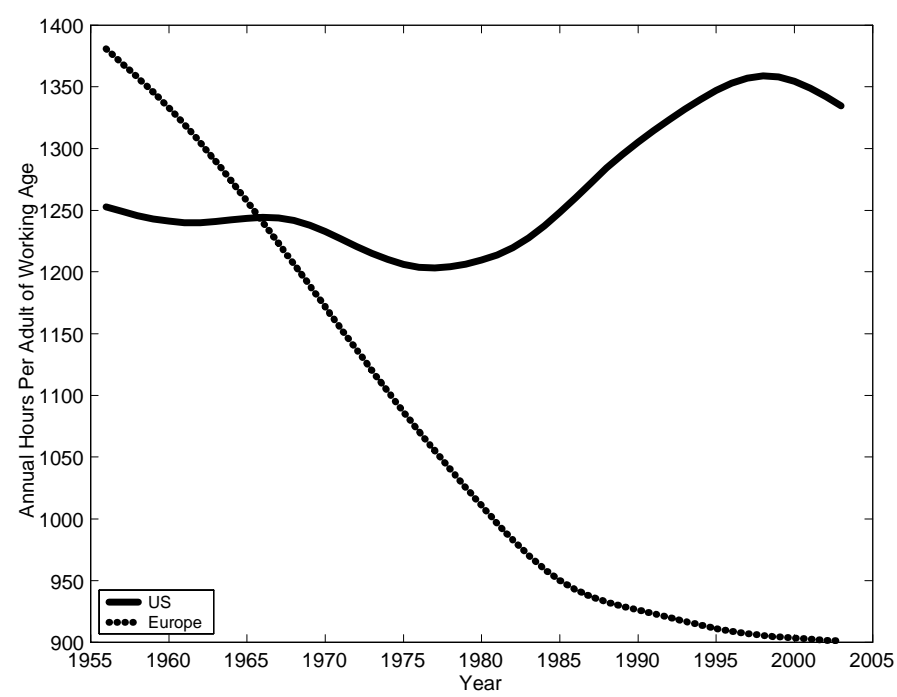

Figure 2.1: Hours Worked in Europe and the US

These two series display dramatically different behavior. Hours worked in Europe are initially higher but then decrease at a fairly steady rate until the mid 1980s, at which point they level out. In contrast, hours worked in the US are relatively flat until the mid 1980s, at which point they experience a fairly steady increase until around 2000.

To better focus on the differences in hours worked across the two countries it is of interest to look at the percent difference in hours worked in Europe relative to the US. This is shown in Figure 2.2

Figure 2.2 illustrates three key points. First, the decline in hours worked in Europe relative the US is a process that proceeded at a relatively constant rate for roughly 40 years beginning (at least) in the mid 1950s. Second, the magnitude of the decline is large: hours worked in Europe decline by almost $45 \%$ relative to the US. Third, although hours worked in Europe and the US are similar in the late 1960s, hours worked are not similar prior to this date.

While I will not make any use of it in the subsequent analysis, it is perhaps of interest to assess the relative importance of declines in employment to population ratios and hours per worker in employment. ${ }^{3}$ As shown in Figure 3, the declines are roughly comparable.

\subsection{Unemployment in the US and Europe}

Figure 2.4 shows the evolution of the differential in unemployment rates between the US and the three European countries being studied here. As noted earlier, there is a

\footnotetext{
${ }^{3}$ Rogerson (2004) documents the change in employment and unemployment rates between Europe and the US. Mortensen and Pissarides (1999b) had earlier noted that differences in participation rates were much larger than differences in unemployment rates.
} 


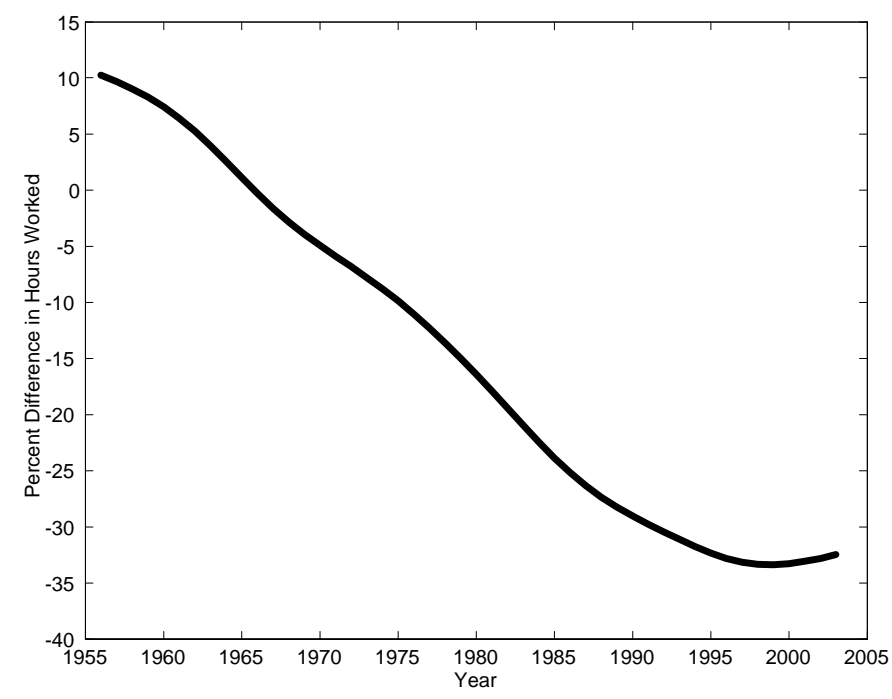

Figure 2.2: Percent Difference in European Hours Worked Relative to US

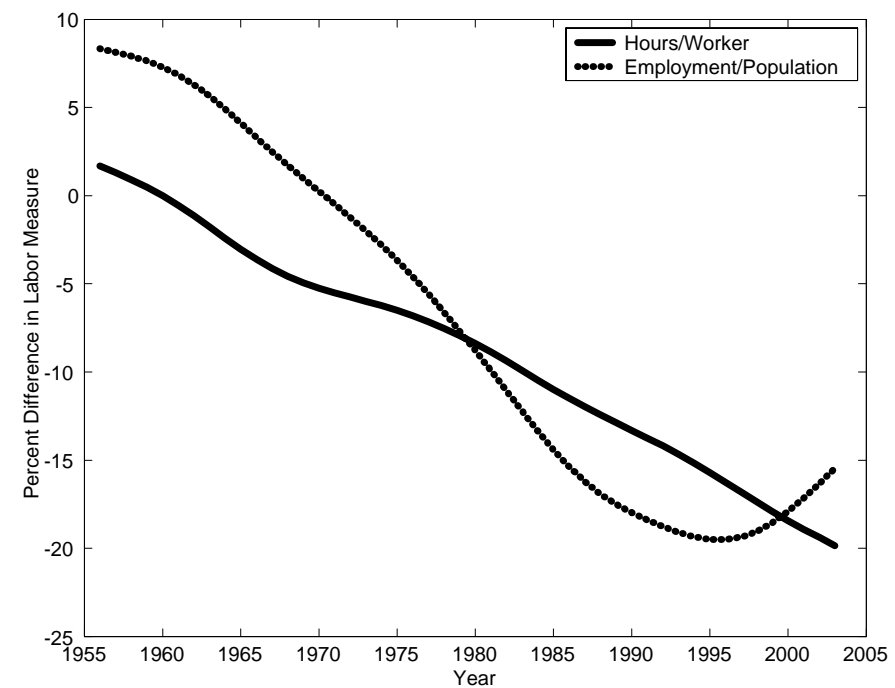

Figure 2.3: Components of Hours Worked in Europe Relative to the US 


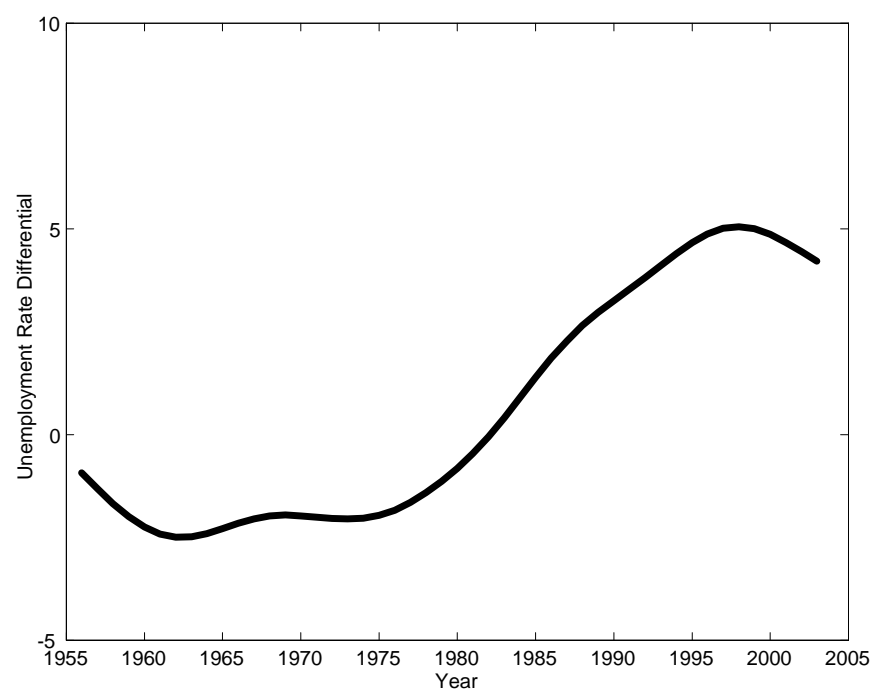

Figure 2.4: Unemployment Rate Differential

very large literature that examines the evolution of unemployment in Europe relative to the US. This literature emphasizes that beginning in the mid 1970s, unemployment in Europe increases very significantly relative to the US and remains high up to the present time.

Figure 2.4 confirms the findings of the earlier literature. Prior to the mid 1970s the unemployment rate differential is relatively constant, with unemployment being somewhat lower in Europe, but beginning in the mid 1970s this differential increases gradually through to the late 1990's, at which point the differential is around $5 \%$.

\subsection{Comparing Hours and Unemployment Evolutions}

One key difference between the evolution of hours worked differences and unemployment rate differences concerns timing. Although the picture of unemployment rate differentials shows little change prior to the mid 1970s, hours worked in Europe decline relative to the US since the mid 1950s, with no evidence of anything noteworthy about the period from the mid 1970s on.

A second key difference concerns magnitudes. A simple calculation allows us to gauge the importance of the evolution of the unemployment rate differential in accounting for the evolution of the differential in hours of work. First, I choose 1970 as the benchmark year. ${ }^{4}$ Next, consider a year different than the benchmark year, say 1990. I take the increase in the unemployment rate from 1970 to 1990 and ask by how much hours worked in 1990 would increase if the unemployment rate had remained at its 1970 level and all of the excess unemployed workers were assumed to be employed and worked the

\footnotetext{
${ }^{4}$ Other choices for the benchmark year lead to the same conclusion.
} 


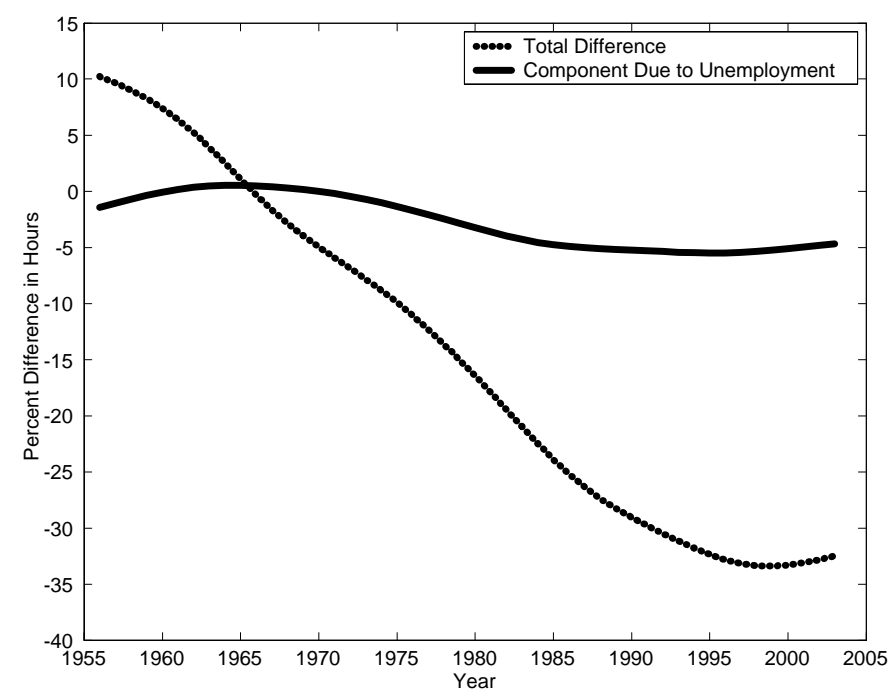

Figure 2.5: Role of Unemployment in Accounting for Differences in Hours of Work

same number of hours as an average employed worker in 1990. Doing this for each year we can construct a time series showing the effect of changes in the unemployment rate on the hours of work differential. The results are shown in Figure 2.5, along with the information from Figure 2.2 showing the actual differences in hours worked in Europe relative to the US.

The picture shows that unemployment can account for only a very small fraction of the total changes over the time period, and that this remains true even if we focus on the period since 1975 .

Two conclusions follow. First, between 1956 and 2003 there has been an enormous change in relative time devoted to market work in Europe and the US, and this change has occurred at roughly a steady pace from 1956 through the mid 1990s. Second, even if we could perfectly account for the different evolutions in unemployment, this would be of little help in accounting for these changes in time devoted to market work.

\section{Structural Transformation and the Role of Services}

The previous section documented a steady decline of hours worked in Europe relative to the US since 1956. If less time is being devoted to market production in Europe relative to the US, it is potentially of interest to ask which activities are not being done. If the decreases are concentrated among a given set of activities this information may help to shed light on potential sources of the decrease. This section presents evidence to establish two points. First, the decline in hours worked in Europe relative to the US is largely accounted for by the fact that as Europe catches up to the US in terms of overall productivity, it does not develop a market service sector of the same magnitude 


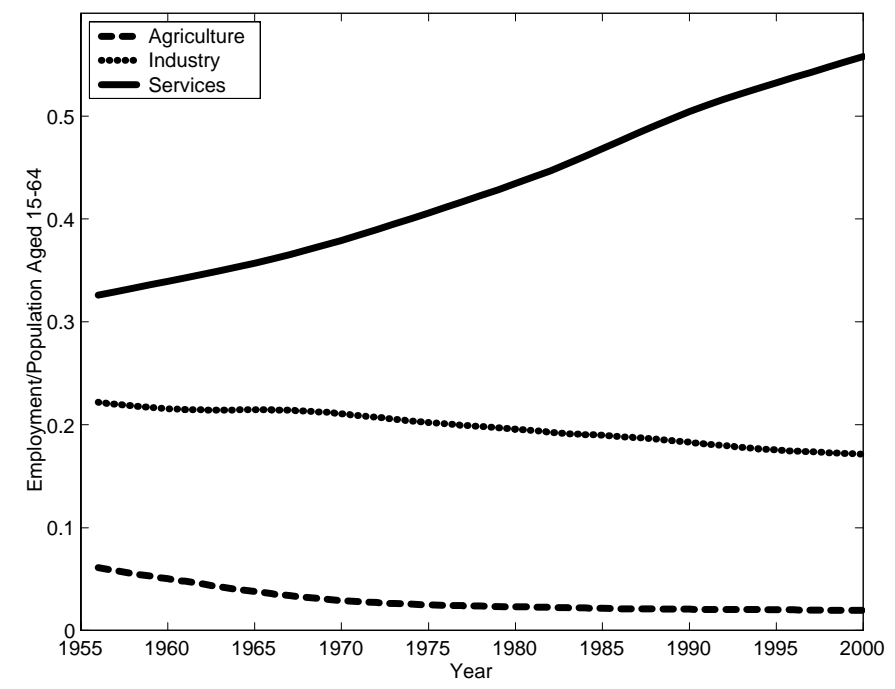

Figure 3.1: Structural Transformation in the US

as the US. Second, Europeans currently spend more time in home production than do Americans, thereby offsetting some of the differences in time devoted to market work.

\subsection{Market Work by Sector}

I consider three broad sectors-agriculture, industry and services, and for each sector I compute a sectoral employment rate which is total sectoral employment divided by total population aged $15-64 .^{5}$ I focus on employment rather than hours for two reasons. First, complete time series on hours by sectors for all four countries are not available, and second, the data that is available shows that hours per employed worker move similarly across sectors, so that movements in relative sectoral hours across countries are dominated by movements in relative employment rates.

It is important to be aware of the process of structural transformation that accompanies development when comparing sectoral employment rates. Specifically, as emphasized by Kuznets, early on in the development process an economy devotes most of its labor to the agricultural sector. In the early phases of development, the economy reallocates labor from the agricultural sector to both the industry and service sectors. Later, the economy enters a phase of development where it reallocates labor from both the agriculture and industry sector into the service sector. Figures 3.1 and 3.2 show how sectoral employment rates have evolved in the US and Europe since 1956.

\footnotetext{
${ }^{5}$ I note that the concept of sectoral employment rates are distinct from the concept of sectoral employment shares. The former has population in the denominator and sum to the employment to population ratio, whereas the latter has employment in the denominator and therefore sum to one. Data for sectoral employment is taken from the OECD Data Base and the 2001 issue of the OECD Historical Statistics.
} 


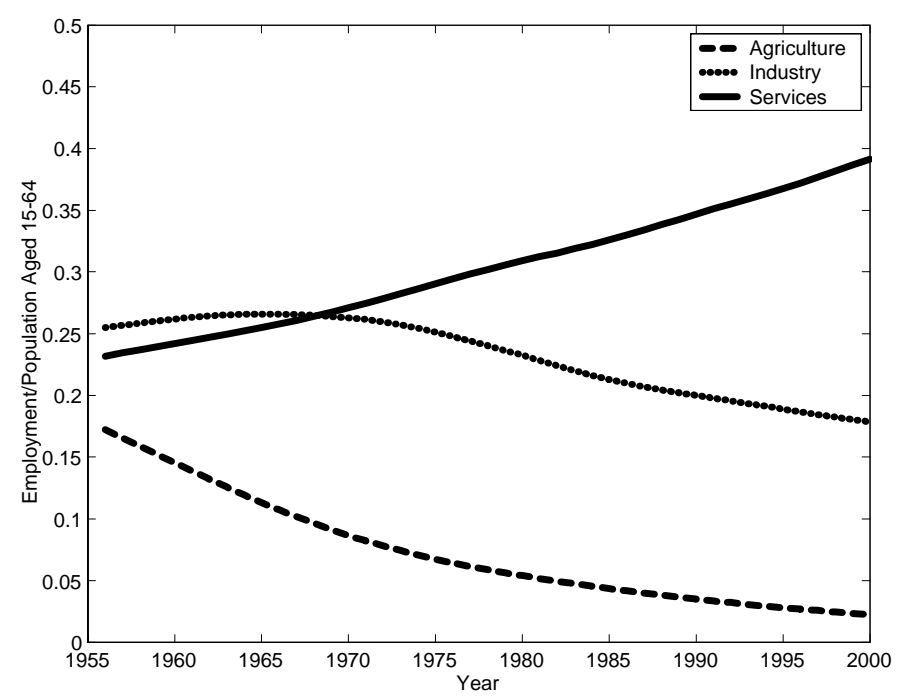

Figure 3.2: Structural Transformation in Europe

Consistent with Kuznets' description, in both cases the service sector employment rate increases throughout the period and the agriculture sector employment rate decreases throughout the period. The sectoral employment rates for industry behave differently in the two figures. In the US, this rate decreases throughout the entire period, while for Europe it actually increases modestly until the late 1960s before starting to decrease. One interpretation of this difference is that the US is in the second phase of the structural transformation during the entire period, while Europe passes from the first phase to the second phase during the late 1960s. Given that Europe lags in the development process in the mid 1950s but largely catches up to the US by the end of the period, this interpretation seems reasonable.

Although both economies display the same qualitative features of the structural transformation that Kuznets emphasized, we next show that there is a pronounced quantitative difference between the two. To see this, Figure 3.3 shows the sectoral employment rates for Europe relative to the US, defined as the ratio of the two values. For ease of presentation, in this graph we combine industry and agriculture.

The picture reveals a striking finding. Given that Europe lags the US in the development process in 1956, one expects Europe to have relatively high employment in agriculture and industry and relatively low employment in services, and indeed, this pattern is found in the data. Over the subsequent 45 years, as Europe virtually catches up to the US in terms of development (measured as output per hour), holding all else constant we would expect that Europe's relative employment levels should converge to US levels. But, while this occurs in agriculture and industry, we see that the relative employment level in services remains flat at roughly .70 for the entire period.

Put somewhat differently, as of 2000, Europeans have both lower employment rates 


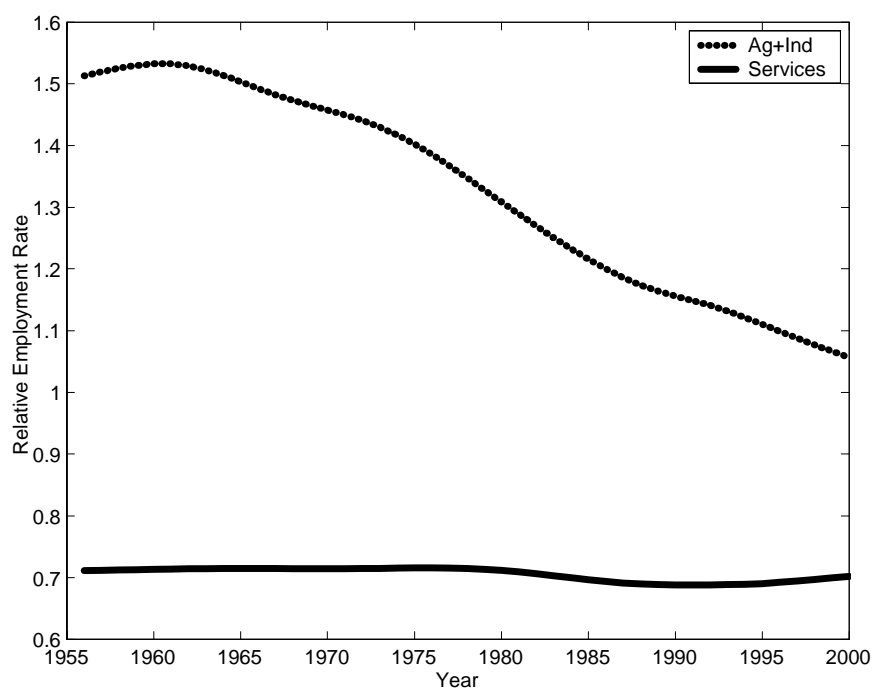

Figure 3.3: Relative Sectoral Employment Rates in Europe

and lower levels of annual hours worker per person in employment. But, as Table 1 shows, the discrepancy in employment levels is accounted for almost exclusively by differences in employment in services.

Table One

European Employment Rate Differential With US

\begin{tabular}{cccc}
\hline \hline Year & Agriculture & Industry & Services \\
\hline \hline 1956 & 11.2 & 3.4 & -9.4 \\
2000 & 0.5 & 1.2 & -15.5
\end{tabular}

It seems that any theory that seeks to account for the different evolution of total hours worked in Europe and the US must be able to also explain why the differences are so skewed toward services.

\subsection{Homework versus Market Work}

The previous section analyzed the differing evolutions of market work across sectors and noted that differences in 2000 were largest in the service sector. One distinguishing feature of many activities in the market service sector is that they have good nonmarket substitutes. Examples include child care, cooking, cleaning, house repairs, yard maintenance, and elderly care. In view of this it is of interest to examine the extent to which differences in market work are offset by compensating differences in nonmarket work. Unfortunately, data availability prevents a time series analysis of cross-country patterns. However, in this section I briefly summarize findings in several recent papers which provide useful information about differences in recent cross-country analyses. 
Three different studies offer information about recent cross-country differences in home and market work based on time use studies. A common finding is that differences in market work are indeed significantly offset by differences in homework, though the extent of this offset varies across studies. In the most extreme case, Freeman and Schettkat (2002) find that total hours of work for adults is roughly the same for Germans and Americans, with the only difference being the allocation of these hours between home and market work. This study also shows that the patterns of consumer expenditure differs in a corresponding fashion, i.e., Germans spend more time on meal preparation at home and spend less money at eating establishments. Olovsson (2004) found a similar result for time allocations between Sweden and the US: additional home work made up for $90 \%$ of the discrepancy in market hours between Swedes and Americans. Lastly, using data from the recent Harmonized Time Use Study, Ragan (2005) compares several European countries with the US and finds that Europeans engage in more homework than do Americans, and that this increase in homework offsets about one third of the differences in time devoted to market work. ${ }^{6}$

Related work has also been carried out by Davis and Henrekson (2004). Consistent with the economic mechanism that will be discussed later in the paper, they show that countries with higher marginal tax rates systematically have lower employment in those market activities for which there are good nonmarket substitutes.

\section{A Model of Time Allocation}

This section develops a simple model of time allocation to account for the process of structural transformation. In the following sections, the model is calibrated to match the process of structural transformation in the US and then used to assess the effect of taxes and technology on hours worked in Europe over time. The model will emphasize two factors that display steady ongoing change over the period 1956-2000: changes in government tax and spending programs, and changes in technology. Technological change will encompass both changes in relative productivities across market sectors as well as between the home and market sectors.

\subsection{Model}

A key criterion for the model is that it be able to generate the change in hours worked across sectors associated with the process of structural transformation. Two main classes of models have been used in the literature to produce this outcome. The first class emphasizes non-homotheticities in preferences-if income elasticities are not all unitary then as an economy becomes richer it will change the allocation of resources across sectors.

\footnotetext{
${ }^{6}$ Alesina, Glaeser and Sacerdote (2005) present data from another source which challenges this conclusion. As noted by these authors, however, their data set seems ill-suited to cross-country comparisons. The Harmonized Time Use data set used by Ragan was designed to specifically address the shortcominings mentioned by Alesina et al, and hence seems more reliable.
} 
Examples following this approach include Echevarria (1997), Kongsamut, Rebelo and Xie (2001) and Gollin, Parente and Rogerson (2005). A key implication of this class of models is that technological change which is neutral across sectors can produce ongoing reallocation of activity across sectors. The second class of models stresses uneven technological progress across sectors-if relative productivities are changing across activities and substitution elasticities across goods are not unitary, then labor will be reallocated across activities. Baumol (1967) is an early example of this class, while Ngai and Pissarides (2004) provide a recent generalization. A noteworthy feature of this approach is that it can generate a structural transformation with homothetic preferences, as long as the elasticity of substitution between goods is not unity.

The model adopted here is a hybrid of these two approaches. Non-homotheticities will be central to the reduction of hours worked in agriculture, but uneven technological progress will be central to the movement of resources from industry into services. This hybrid approach is motivated by two factors. First, Ngai and Pissarides find that uneven technological change can account for much of the reallocation between industry and services but is not sufficient to explain the reallocation of resources out of agriculture. Second, the presence of a non-hometheticity in preferences produces a mechanism whereby hours of work decrease with development at low levels of productivity. ${ }^{7}$

The model is effectively a sequence of static time allocation problems. Preferences are assumed to be constant over time and across economies, but productivitities and tax rates will be allowed to differ. The focus of the analysis is on how these factors affect time allocations. To ease notation in what follows I suppress time subscripts and focus on the time allocation problem solved in a particular period.

There is a representative household with preferences given by:

$$
U(C, 1-H)+V(A)
$$

where $C$ is a composite good representing consumption of non-agricultural goods and services, $H$ is total time allocated to work ( $1-H$ is leisure), and $A$ is consumption of agricultural goods. The function $U$ is assumed to be log-linear in $C$ and $1-H:^{8}$

$$
U(C, 1-H)=a_{C} \log (C)+\left(1-a_{C}\right) \log (1-H)
$$

The composite consumption good $C$ is defined by:

$$
C=\left[a_{I} I^{\varepsilon}+\left(1-a_{I}\right) F(S, N)^{\varepsilon}\right]^{1 / \varepsilon}
$$

where $I$ is consumption of goods produced in the industrial sector, and $F$ is an aggregate

\footnotetext{
${ }^{7}$ Based on data in Maddison (1995), all current rich countries experienced decreases in time devoted to work via the margin of shorter workweeks during the first half of the 20th century.

${ }^{8}$ Note that as the size of the agricultural sector becomes small, these preferences are consistent with balanced growth.
} 
of market services $(S)$ and nonmarket production $(N) .{ }^{9}$ We further assume that the aggregator $F$ is also CES:

$$
F(S, N)=\left[a_{S} S^{\eta}+\left(1-a_{S}\right) N^{\eta}\right]^{1 / \eta} .
$$

Utility derived from the consumption of agricultural products, $V(A)$, is assumed to take a very simple form. Specifically, it is assumed that individuals do not desire more than $\bar{A}$ units of the agricultural good, but also that they require consumption of at least this amount, i.e., $V(A)=\min \{A, \bar{A}\}$ if $A \geq \bar{A}$ and that $V(A)=-\infty$ if $A<\bar{A}$. In equilibrium this will imply that the allocation of labor to agriculture is completely determined by productivity in agriculture and hence that the movement of labor out of agriculture is completely determined by improvements in agricultural productivity.

Next we turn to a description of technology. For simplicity we abstract from capital and assume that all technologies are linear in labor:

$$
I=A_{I} H_{I}, A=A_{A} H_{a}, S=A_{S} H_{S}, N=A_{N} H_{N} .
$$

where the $H_{i}$ are the time allocations to sector $i$, and the $A_{i}$ are productivity parameters. ${ }^{10}$

As noted earlier, we also allow for a government in the model. We assume that there is a proportional tax rate levied on labor income from market work at rate $\tau$, and that this tax is used to finance a lump-sum transfer $T$ to the representative agent. ${ }^{11}$

\subsubsection{Equilibrium}

I study a competitive equilibrium for this economy. With the linear production technologies one can determine all of the prices based on the technology parameters. Specifically, if we normalize the wage rate to one, it follows that the prices of the agricultural good $\left(P_{A}\right)$, the industrial good $\left(P_{I}\right)$ and (market) services $\left(P_{S}\right)$ must be the inverse of the respective productivity in each activity:

$$
P_{A}=\frac{1}{A_{a}}, P_{I}=\frac{1}{A_{I}}, P_{S}=\frac{1}{A_{S}}
$$

\footnotetext{
${ }^{9}$ Implicitly we assume that most nonmarket production consists of services that are substitutable with market provided services. One could easily allow for the possibility that industrial goods can be produced at home, but as an empirical matter this does not seem to be a particularly important component of production in rich economies, and hence we abstract from it.

${ }^{10}$ Since we abstract from capital, differences in labor productivity implicitly incorporate differences due to capital as well as due to technology adoption, regulation, etc.

${ }^{11}$ Given that the home sector produces a good substitute for market services and is not taxed, one could also interpret home activity in the model to include unreported activities as well. It is plausible to think that the act of operating outside of the market makes the services imperfect substitutes for those produced in the market, and that a different technology must be used.
} 
Taking these prices and the transfers from the government as given, in equilibrium the representative agent chooses values of consumption $(A, I, S, N)$, time allocated to market work $\left(H_{M}\right)$ and time allocated to home work $\left(H_{N}\right)$ to maximize:

$$
U\left(C, 1-H_{M}-H_{N}\right)+V(A)
$$

subject to the constraints:

$$
\begin{aligned}
P_{I} I+P_{S} S+P_{A} A & =(1-\tau) H_{M}+T \\
N & =A_{N} H_{N} \\
H_{M}+H_{N} & \leq 1
\end{aligned}
$$

plus nonnegativity constraints.

Equilibrium also requires an allocation of market time across sectors that is consistent with market clearing:

$$
A=A_{A} H_{A}, I=A_{I} H_{I}, S=A_{S} H_{S}, H_{M}=H_{A}+H_{I}+H_{S}
$$

and a value of transfers that is consistent with the government budget constraint:

$$
T=\tau H_{M}
$$

One can combine the first order conditions for the consumer maximization problem with the market clearing conditions and the government budget constraint to obtain the following four equations that implicitly characterize the equilibrium allocation of time across activities:

$$
\begin{gathered}
\frac{a_{S}}{1-a_{S}}\left[\frac{S}{N}\right]^{(\eta-1)}=\frac{A_{N}}{(1-\tau) A_{S}} \\
\frac{\left(1-a_{I}\right) a_{S}}{a_{I}} \frac{F(S, N)^{(\varepsilon-\eta)} S^{\eta-1}}{I^{\varepsilon-1}}=\frac{A_{I}}{A_{S}} \\
a_{C} a_{I}(1-\tau) A_{I} C^{-1} I^{\varepsilon-1}=\frac{1-a_{C}}{1-H} \\
H_{A} A_{A}=\bar{A}
\end{gathered}
$$

The first equation states that the marginal rate of substitution between home and market services is equal to the (tax-distorted) marginal rate of transformation between home and market services. The second equation states that the marginal rate of substitution between industrial goods and (market) services is equal to the marginal rate of transformation between the industrial good and (market) services. Note that since taxes affect these two activities equally, the tax rate does not explicitly enter this expression. The third equation states that at the margin, the consumer is indifferent between working 
more in the industrial sector and taking more leisure. Of course, given the first two equations, this indifference extends to the consideration of working additional time in any of the sectors. Finally, the fourth equation states that output from the agricultural sector is equal to the food requirement, $\bar{A}$. Given the form of the utility function for utility derived from food there is no standard marginal condition for time devoted to agriculture.

The last equation can be solved for the value of $H_{A}$, leaving three equations in the three unknowns $H_{I}, H_{S}$, and $H_{N}$. Moreover, simple algebraic manipulation shows that the first equation can be used to derive a linear relationship between $H_{N}$ and $H_{S}$ :

$$
H_{N}=\frac{A_{S}}{A_{N}}\left[\frac{a_{S}}{\left(1-a_{S}\right)} \frac{A_{S}}{A_{I}}(1-\tau)\right]^{\frac{1}{\eta-1}} H_{S}
$$

It follows that the model can be reduced to solving a system of two equations for the two unknowns $H_{I}$ and $H_{S}$.

For future purposes it is important to note the following implication of the model for time allocations. Given a value of agricultural productivity (which effectively determines $h_{A}$ ), the remaining elements of the time allocation $\left(h_{I}, h_{S}, h_{N}\right)$ are homogeneous of degree zero in the three remaining productivity parameters, $\left(A_{I}, A_{S}, A_{N}\right)$. That is, scaling all three of these productivities proportionately will not change the time allocation. This results from the fact that preferences are homothetic in the non-agricultural allocation. It follows that time allocations alone can only determine productivities in these three activities up to a scale factor.

\subsection{Technological Change in the Home Sector}

In the model just described, an increase in home sector productivity will lead to an increase in hours worked in the home and fewer hours worked in the market service sector. Many researchers (see, e.g., Greenwood, Seshadri and Yorokoglu (2005)) have argued that many technological advances in the home sector are labor saving and lead to less time devoted to home production. In this subsection I describe a variation on the model which can capture this type of mechanism.

Previously we wrote the home technology as $N=A_{N} H_{N}$. Consider instead the specification $N=A_{1 N}+A_{2 N} H_{N}$. In this specification $A_{1 N}$ can be interpreted as an endowment of home produced goods and can capture the essence of labor saving technological progress at home. In this specification, uniform technological progress in $A_{1 N}, A_{2 N}, A_{I}$, and $A_{S}$ holding $A_{A}$ constant will leave the time allocation $\left(H_{I}, H_{S}, H_{N}\right)$ unchanged. Whereas an increase in $A_{2 N}$ holding all else constant will lead to an increase in home hours, an increase in $A_{1 N}$ will lead to a decrease in home hours. The key point

to note is that one can obtain a decrease in time spent in home production either by an increase in home productivity, if it is labor saving, or by a decrease in home productivity, if it is labor augmenting. This is relevant for the exercises that follow because we will be using data on hours of market work to infer technological change in the home sector. 
The above discussion shows that without additional data one cannot infer the direction of technological change in the home that is required to obtain a given profile of hours worked in the market. While it is of independent interest to determine the nature of technological progress in the home sector, I found that the model's implications for the issues addressed here, such as how time allocations respond to taxes, were virtually identical for the two specifications. In view of this, in what follows I will simply assume that all technological progress in the home is labor augmenting, but it should be kept in mind that whether the home sector technology is advancing more slowly or more quickly than the market service technology is ultimately not pinned down by the analysis.

\section{The US Structural Transformation}

In this section the model is calibrated to match the evolution of sectoral labor inputs for the US economy between 1956 and 2000.

\subsection{Labor Input Across Sectors}

Earlier we presented data on the evolution of sectoral employment rates. From the perspective of the model the object of interest is hours worked across sectors. The Groningen Growth and Development Center provides data on annual hours of work by sector for France, Germany, Italy and the US for selected years between 1950 and $2000 .{ }^{12}$ These data are used to produce series for hours of work per person aged 15-64 across sectors in 1956 and $2000 .^{13}$

A few remarks are in order regarding the construction of these statistics. For 2000 there data on hours by sector for all countries. Hours data by sector for the US in 1956 exist, while for Germany there are data for 1955 and 1960, and for France there are data for 1950 and 1960. For Italy there are sectoral employment data prior to 1979 and data on aggregate hours of work, but not a breakdown of total hours by sector. I construct sectoral shares of hours for France in 1955 as the simple average of the 1950 and 1960 values. I impute sectoral hours for Italy by scaling the sectoral values for France by Italian relative employment levels and then scaling these values to match aggregate hours for Italy. ${ }^{14}$ These imputed values for Italy along with the French and German values for 1955 are used to determine the average distribution of hours across

\footnotetext{
${ }^{12}$ The data for 2000 come from the 60 Sector Data Base, and the data for 1956 come from the 10 Sector Data Base.

${ }^{13}$ In these calculations I have included construction in the service sector. The reason for this is that in the US, the construction industry has increasing hours worked over time relative to population and exhibits very low relatively productivity growth, thereby making it more suited to the service sector. The main effect of this change is to increase the gap between productivity growth in services and industry, thereby lowering the calibrated value of $\varepsilon$. Construction is small relative to services so the effect on services per se is quite small.

${ }^{14}$ I scaled the French numbers since aggregate hours per worker in Italy are much closer to France than to Germany in 1956, but the results are very similar if I instead scaled based on the average of Germany and France.
} 
sectors, and are then applied to the total hours of work for Europe in 1956 to determine the European sectoral allocation in 1956.

In the model, time endowment is normalized to one. To map actual hours into fractions of time endowment devoted to work I assume that total time devoted to market work in the US in 1956 is equal to 1/3. Table Two shows the resulting values for sectoral labor input relative to time endowment for both Europe and the US in 1956 and 2000.

\begin{tabular}{|c|c|c|c|c|c|c|c|c|}
\hline \multicolumn{10}{|c|}{ Table Two } \\
\hline \multicolumn{1}{|c|}{ Sectoral Labor Inputs Relative to Time Endowment } \\
\hline & \multicolumn{3}{|c|}{ US } & \multicolumn{5}{c|}{ Europe } \\
\hline & $h_{A}$ & $h_{I}$ & $h_{S}$ & $A g g$ & $h_{A}$ & $h_{I}$ & $h_{S}$ & $A g g$ \\
\hline 1956 & .032 & .089 & .209 & .330 & .097 & .104 & .163 & .364 \\
\hline 2000 & .008 & .057 & .292 & .357 & .010 & .052 & .176 & .238 \\
\hline
\end{tabular}

As described below, the calibration procedure will also require information on time allocated to the home sector in the US in 1956. Aguiar and Hurst (2005b) report that the ratio of home to market work in 1965 is approximately .75, and given this one point estimate we set the fraction of time devoted to the home production in 1956 for the US equal to .25 .

\subsection{Tax Rate Differences}

Computing effective marginal tax rates on labor and how they have changed over time for a representative worker is a difficult task. I do not contribute to the literature on how best to measure these taxes, and instead rely on the estimates that have been provided by others. Mendoza et al (1994) develop a methodology for determining average tax rates on labor, capital and consumption across countries. Data limitations preclude one from carrying out this procedure for years prior to 1965, but for France and Italy there are no data available prior to 1970. In a recent paper, Prescott (2004) modifies the method of Mendoza et al and incorporates progressivity in marginal income tax rates into the analysis. He concludes that effective marginal tax rates on labor in the US were approximately .40 in both the early 1970s and the mid 1990s. ${ }^{15}$ Evidence on government revenues relative to GDP and government spending suggests that tax rates increased modestly in the US during the period 1956-1970. In my calibration I set the tax rate in the US equal to .35 in 1956 and .40 in 2000.

Prescott obtains a marginal tax rate for the three European countries of roughly $60 \%$ in the mid 1990s. Tax rates have been lowered somewhat in the late 1990s, but since economic activity is likely to respond with somewhat of a lag to these decreases, I will consider values of both .55 and .60 for Europe in 2000. Tax rates increased significantly in Europe over the post WWII period. Prescott obtains a rate slightly above .45 for Europe in the early 1970s. In 1960, government receipts as a fraction of GDP is roughly

\footnotetext{
${ }^{15}$ These effective rates incorporate tax rates on consumption.
} 
five percent higher in Europe than it is in the US. Given this information I assume the same differential for tax rates in 1956 and therefore set the European tax rate equal to .40 in 1956.

It is important to note that in terms of the results obtained below what matters is the differences in tax rates over time and across countries, and not the level of the taxes per se. So, the key properties of taxes for what follows is that tax rates in 1956 are $5 \%$ higher in Europe than the US, and that tax rates increase by $5 \%$ in the US and by $15-20 \%$ in Europe.

\subsection{Preference and Technology Parameters}

Given the values for the US tax rates in 1956 and 2000, in this section I show how all preference and technology parameters except for $\eta$ can be calibrated by requiring that the model replicate the US time allocations in 1956 and 2000. Calibrating the model requires setting values for eight technology parameters (four productivities in each of the two periods), and six preference parameters (two elasticity parameters, three share parameters, and the subsistence parameter). Note first that all of the productivity parameters for the initial period can be normalized to one, since this corresponds to a choice of units. Agricultural productivity in 2000 is chosen so as to be consistent with agricultural hours in 2000. We choose productivity in industry and market services for the US in 2000 to match growth in output per hour as reported in the Groningen tensector data base between 1956 and $1997 .{ }^{16}$ The growth rates are $2.47 \%$ and $1.26 \%$ per year for industry and market services respectively. The determination of home sector productivity in 2000 is determined below.

The parameter $\eta$ determines the elasticity of substitution between home and market produced services, and will be important in determining how time is reallocated between the home and the market in response to tax changes and changes in relative productivities. Using aggregate data, McGrattan, Rogerson and Wright (1997) find a value in the range of .40 - .45, while Chang and Schorfheide (2002) find a value in the range of $.55-.60$. Using micro data, Rupert, Rogerson and Wright (1995) find an estimate in the range $.40-.45$, while Aguiar and Hurst (2005a) report an estimate for their benchmark specification in the range of $.55-.60$. These estimates correspond to the elasticity of substitution between all market and nonmarket consumption, while in the model it only refers to the substitutability between market services and home production. To the extent that many of the most easily substitutable components of consumption are services, it seems appropriate to choose a slightly higher value for the elasticity, thus motivating the choice of $\eta=.55 .{ }^{17} \mathrm{I}$ also report results for the cases of

\footnotetext{
${ }^{16}$ The 10 sector data base has data from 1955-1997, whereas the 60 sector data base has data from 1979 onward. Since they have different base years and the ten sector data base covers almost the entire period I have chosen to use the data from a single source.

${ }^{17}$ There are many market services that do not have good nonmarket produced substitutes (e.g., advanced medical procedures). A richer model would incorporate heterogeneity within services to reflect
} 
$\eta=.5$ and $\eta=.6$.

The parameter $\varepsilon$ determines the amount of substitution between goods produced in the industry sector and services and determines how much labor will be reallocated between the industry and service sector in response to uneven changes in productivity growth. If $\varepsilon$ approaches zero, preferences over $I$ and $F(S, N)$ approach a Cobb-Douglas, and in this case there is no reallocation of labor in response to relative productivity changes. To get reallocation from a sector with higher productivity growth to one with lower productivity growth it is necessary for $\varepsilon$ to be negative. As we describe in more detail below, we choose $\varepsilon$ to be consistent with the amount of observed reallocation of labor given observed productivity changes.

Given values of $\eta$ and $\varepsilon$ the four preference parameters $\bar{A}, a_{C}, a_{I}$ and $a_{S}$ are chosen so that the model reproduces the 1956 time allocation for the US displayed previously, including the target of $h_{N}=.25$. The two remaining parameters to be set, the elasticity parameter $\varepsilon$, and the productivity of the home sector in 2000, are chosen to match the time allocations in industry and market services in $2000 .{ }^{18}$ For the benchmark calibration with $\eta=.55$, this implies a value of $\varepsilon=-2.65$.

As noted earlier, what is significant about the home and market sectors is the direction of time allocation and not the direction of technological change. If time allocated to homework decreases, this can be due to either faster technological growth in the home sector if it is of the labor saving variety, or to slower technological change if it affects labor productivity at the margin. Although time devoted to homework in the US in 1956 is used in the calibration procedure, time devoted to homework in 2000 is not. The calibration implies that time spent in nonmarket services is .1871, which corresponds to a decline of approximately $25 \%$ over the period 1956-2000. This is similar to the decline noted by Aguiar and Hurst (2005b). ${ }^{19}$ Assuming only labor augmenting technological change in the home sector, this decrease in time spent at home requires that home productivity grew more slowly than market service productivity. In fact, the calibration requires that home productivity decreases marginally over the 44 year period. Of course, if home productivity growth were all labor saving then technological change must have been more rapid than the $1.26 \%$ experienced in the market service sector. $^{20}$

Table Three shows the parameter values implied by the calibration procedure. Rather

this fact, but the above value is chosen to reflect that at the margin there is substantial opportunity for substitution between home and market produced services.

${ }^{18}$ Loosely speaking, one can think of choosing the value of $\varepsilon$ so as to match the time devoted to industry in 2000 and then choosing the technology in nonmarket production in 2000 to match the time devoted to market services.

${ }^{19}$ Aguiar and Hurst (2005) report a drop of roughly 30\% between 1965 and 2003 per person aged 21-65. It seems likely that the per-person decrease would be less if we included individuals aged 15-20. In any case, given the various measurement issues involved, the model's prediction does not seem to be greatly at odds with the available data.

${ }^{20}$ To the extent that technological regress in the home sector is not plausible, this suggests that at least some of the technological progress must have been of the labor saving variety. 
than report the level of the technology parameters in 2000 I have reported the implied annual growth rates (in percent), denoted by $\gamma_{i}$ for sector $i$.

\begin{tabular}{|c|c|c|c|c|c|c|c|c|c|}
\hline \multicolumn{11}{|c|}{ Table Three } \\
\hline \multicolumn{10}{|c|}{ Calibrated Values for the US Economy } \\
\hline-2.65 & $\eta$ & $\gamma_{A}$ & $\gamma_{I}$ & $\gamma_{S}$ & $\gamma_{N}$ & $a_{C}$ & $a_{I}$ & $a_{S}$ & $A$ \\
\hline & 3.26 & 2.47 & 1.26 & -0.2 & .63 & .02 & .59 & .032 \\
\hline
\end{tabular}

It is of interest to examine how the calibrated model accounts for the changes in time devoted to market work in the US between 1956 and 2000. As seen in Table Two, market work in the US increases by almost 10\% during this time period, despite the fact that taxes are assumed to increase by $5 \%$. The model is able to generate a substantial increase in market work despite the tax increase by having a movement of activity from the home sector into the market sector that is driven by changes in technology. According to the calibrated model, if home technology had grown at exactly the same rate as the market service sector technology but all other changes were kept in place, then market hours in the US would have fallen by more than $15 \%$ over the period 1956 2000 . Of this $15 \%$, roughly $2 / 3$ of the decrease is due to the increase in tax rates, while the remaining third is due to the increase in productivity in agriculture interacting with the homotheticity in preferences. Moreover, the increase in the size of the market service sector would have been almost zero, as the movement out of industry and into market services associated with uneven technological progress would have been virtually offset by the increase in taxes.

\section{Accounting for Hours of Work in Europe}

In this section we use the calibrated model to interpret hours of work in Europe in 1956 and 2000. Throughout this analysis we assume that preference parameters in Europe are the same as in the US, but allow that tax rates and productivities may differ. The goal of the exercise carried out here is to assess the role of differences in technology and taxes in accounting for the differences in hours worked in Europe and the US in 1956 and 2000. While it would seem that a natural exercise would be to solve the model using sectoral productivities for Europe in 1956 and 2000, given values for tax rates in Europe in 1956 and 2000, this is not possible. The reason is that systematic sectoral accounts that permit cross-country comparisons of sectoral productivity have not yet been developed. Whereas aggregate productivity comparisons such as those provided by the Penn World Tables can be carried out using only prices for final goods and investment, one would also need international prices for all intermediate inputs to compute sectoral relative productivities. Absent accounts that explicitly address this issue, the numbers that one obtains from various exercises are not reliable. ${ }^{21}$ Additionally, home sector productivity

\footnotetext{
${ }^{21}$ This is evidenced by the exchange between Bernard and Jones (1996) and Sorensen (2001), which showed how comparisons based on one particular procedure are very sensitive to assumptions about base year because of changes in relative prices.
} 
is a potentially important parameter and there is no data available to measure this productivity. Given these issues, I will simply carry out several calculations based on different scenarios for relative productivities.

\subsection{Accounting for Europe in 1956}

In this section I assess the role of technology and taxes in accounting for the European time allocations in 1956. I assume a tax rate of .40 for Europe in 1956, and that agricultural productivity in Europe is such as to generate time devoted to agriculture that is equal to that in the data. It remains to provide values for productivities in the other sectors. I consider three cases. Using output per worker from the PWT and hours per worker in employment from the GGDC, I compute that output per hour in Europe was .46 that of the US in 1956. In each case considered I require that aggregate output per hour in Europe in 1956 is equal to .46 of the US value in 1956 in the calibrated model. ${ }^{22}$ Case 1 assumes that all three of $A_{I}, A_{S}$, and $A_{N}$ are uniformly lower relative to their US values. Given the forces in the model, we know that such a specification cannot account for why Europe lags the US in the structural transformation of activity from industry to services, but it is a useful benchmark nonetheless. Case 2 assumes that $A_{S}$ and $A_{N}$ are uniformly lower in Europe relative to the US, but $A_{I}$ is allowed to have a different relative value. Specifically, taking the US growth rates for $A_{I}$ and $A_{S}$ used in the calibration, I solve for the values of $A_{I}$ and $A_{S}$ that correspond to Europe lagging the US by a given number of years subject to matching the value for aggregate relative productivity. This implies that Europe lags the US by 38 years in 1956, and that $A_{I}=.40$, and $A_{S}=.62$. (Recall that all productivities are normalized to one for the US in 1956.) This calculation implicitly assumes that home productivity grew at the same pace as productivity of market services prior to 1956, so that the uneven technological change experienced between 1956 and 2000 is specific to that period. ${ }^{23}$ Lastly, Case 3 solves for the values of the technology parameters that would perfectly reproduce the values of time devoted to market activities in Europe in 1956. Results are presented in Table 4.

\footnotetext{
${ }^{22}$ I measure GDP using the prices from the calibrated model for the US in 2000.

${ }^{23}$ To the extent that this uneven technological change largely manifests itself as an increase in hours of work by married women, this seems a reasonable assumption.
} 


\begin{tabular}{|c|c|c|c|c|c|}
\hline \multicolumn{7}{|c|}{ Table 4 } \\
\hline \multicolumn{7}{|c|}{ 1956 European Time Allocation } \\
\hline & US Data & Eur Data & Case 1 & Case 2 & Case 3 \\
\hline$H_{M}$ & .330 & .364 & .351 & .363 & .364 \\
\hline$H_{A}$ & .032 & .097 & .097 & .097 & .097 \\
\hline$H_{I}$ & .089 & .104 & .079 & .103 & .104 \\
\hline$H_{S}$ & .209 & .164 & .175 & .164 & .164 \\
\hline$A_{I}$ & - & - & .5 & .40 & .40 \\
\hline$A_{S}$ & - & - & .5 & .62 & .63 \\
\hline$A_{N}$ & - & - & .5 & .62 & .63 \\
\hline
\end{tabular}

As expected, Case 1 fails to account for the fact that in 1956 Europe has relatively greater time allocated to industry and less to services. Instead, Europe devotes less time to both activities. Two factors are at work here. One is that the greater time devoted to agriculture in Europe decreases the time available to other activities, and the second is that the higher tax rate in Europe discourages market work. This second effect is much greater for services than for industry given the presence of nonmarket substitutes for the former. However, despite this shortcoming, it is of interest to note that Case 1 does account for much of the observed difference in total time devoted to market work. The key force in the model behind this outcome is the nonhomotheticity in preferences associated with the subsistence constraint on agricultural consumption. ${ }^{24}$

Case 2 has Europe lagging more in industry than in services in 1956, and thereby is capable of accounting for the fact that Europe lags in the process of moving labor from industry to services. In fact, Case 2 comes very close to exactly matching the 1956 time allocation for Europe. Total market work is somewhat higher in Case 2 than in Case 1 because less time is devoted to producing services and hence the effect of higher taxes on market work is somewhat smaller. Loosely speaking one can understand one of the effects of higher taxes as moving a certain percentage of market service work into the home sector. Given the close match between Case 2 and the actual time allocation in Europe, it is not surprising that Case 3 virtually reproduces the technology parameters from Case 2, and therefore merits little additional discussion.

The main message to be taken away from this exercise is that practically all of the differences in time allocations between Europe and the US in 1956 seem to be consistent with a simple story in which Europe lags the US in terms of technology and has a somewhat higher tax rate.

The above results were for the benchmark case of $\eta=.55$. Table 5 shows how the results of Case 2 are affected by considering alternative values of $\eta$.

\footnotetext{
${ }^{24}$ More generally, one could have a subsistence constraint that involved some component of consumption of the industrial good and services in additional to the agricultural good. This would soften the implication of the current specification that it is only low productivity in agricultural that leads to higher hours of market work.
} 


\begin{tabular}{|c|c|c|c|}
\hline \multicolumn{4}{|c|}{ Table 5} \\
\hline \multicolumn{4}{|c|}{ Effect of Changes in $\eta$} \\
\hline & $\eta=.5$ & $\eta=.55$ & $\eta=.60$ \\
\hline$H_{M}$ & .364 & .363 & .362 \\
\hline$H_{I}$ & .101 & .103 & .104 \\
\hline$H_{S}$ & .167 & .164 & .162 \\
\hline
\end{tabular}

The message of this table is that the results are not very sensitive to small changes in $\eta$. In all cases one would conclude that the tax and technology specification in Case 2 does a very good job of replicating the time allocation in Europe.

It is also of interest to consider the counterfactual of what time allocations in Europe would have looked like if Europe had different tax rates in 1956. Table 6 shows the results for two counterfactuals: the case in which Europe had the same tax as the US in 1956, and a second in which Europe had the same tax rate in 1956 as in 2000, here assumed to be .55 . These calculations are carried out assuming the technologies are those generated by Case 3 in Table 4.

\begin{tabular}{|c|c|c|c|c|}
\hline \multicolumn{5}{|c|}{ Table 6 } \\
\hline \multicolumn{5}{|c|}{ Taxes and the 1956 European Time Allocation } \\
\hline & Data for 1956 & \multicolumn{2}{c|}{ Model } \\
\hline & US & Europe & $\tau=.35$ & $\tau=.55$ \\
\hline$H_{M}$ & .330 & .364 & .387 & .291 \\
\hline$H_{A}$ & .032 & .097 & .097 & .097 \\
\hline$H_{I}$ & .089 & .104 & .108 & .089 \\
\hline$H_{S}$ & .209 & .164 & .183 & .105 \\
\hline
\end{tabular}

Table 6 shows that if Europe had the same tax as the US in 1956 then hours of market work would have been more than $16 \%$ higher than in the US, rather than $9 \%$ higher as in the actual data. The implication is that even in the absence of changes in tax and spending policies, hours of market work in Europe would have fallen by this amount due simply to the process of technological catch-up. Changes in hours of work in the US prior to 1956 provide some evidence in support of such an effect. Using data from the US Census, Owen (1986) computes hours of work per adult in 1920 and 1960. Assuming that Europe lags the US by 38 years in 1956, this time span represents a comparable lag. Over this period Owen reports that hours of market work per adult of working age dropped by slightly more than $20 \%$.

The last column of Table 6 shows that if Europe in 1956 had the tax and spending programs that were in place in 2000, hours of work would have been almost $20 \%$ lower than in the data, and more than $10 \%$ below those in the US. For the same reason as noted earlier, taxes have a somewhat smaller impact on hours of work in the 1956 context than in the 2000 context, due to the smaller role played by the market service sector. 


\subsection{Accounting for Europe in 2000}

Next we turn to the European time allocation in 2000. I follow a similar procedure as in the previous subsection. First, I assume that productivity in agriculture is chosen so as to generate the same time allocated to agriculture as in the data. Second, I require in each case that aggregate output per hour calculated using prices from the 2000 calibration to the US economy be equal to .96 of the US value, consistent with the corresponding figure based on the Penn World Tables data on output per worker and the Groningen data on hours per employed person. Because European productivities are so close to those of the US, I only consider two cases. Case 1 assumes that all three values of $A_{I}, A_{S}$, and $A_{N}$ are uniformly lower than in the US. Case 2 chooses values of the productivities so as to perfectly match the European time allocations. For each case I do the calculations both for $\tau=.55$ and for $\tau=.60$. The results are contained in Table 7.

\begin{tabular}{|c|c|c|c|c|c|c|}
\hline \multicolumn{7}{|c|}{ Table 7 } \\
\hline \multicolumn{7}{|c|}{2000 European Time Allocation } \\
\hline & \multicolumn{2}{|c|}{ Data } & \multicolumn{4}{c|}{ Model } \\
\hline & & & \multicolumn{2}{c|}{$\tau=.60$} & \multicolumn{2}{c|}{$\tau=.55$} \\
\hline & US & Europe & Case 1 & Case 2 & Case 1 & Case 2 \\
\hline$H_{M}$ & .357 & .238 & .231 & .238 & .265 & .238 \\
\hline$H_{A}$ & .008 & .010 & .010 & .010 & .010 & .010 \\
\hline$H_{I}$ & .057 & .052 & .045 & .052 & .048 & .052 \\
\hline$H_{S}$ & .292 & .176 & .176 & .176 & .207 & .176 \\
\hline$A_{I}$ & - & - & .97 & .80 & .97 & .91 \\
\hline$A_{S}$ & - & - & .97 & 1.02 & .97 & .98 \\
\hline$A_{N}$ & - & - & .97 & .99 & .97 & 1.26 \\
\hline
\end{tabular}

We begin by discussing the results for Case 1. There are two key points to note. First, the model implies that tax rates can account for the bulk of the differences in aggregate hours of market work. Specifically, when $\tau=.6$ the model predicts a fall in hours that slightly exceeds that found in the data, whereas when $\tau=.55$ the drop in hours relative to the US is about $80 \%$ of that found in the data. This conclusion is very similar to that reached by Prescott (2004). Second, the model predicts that the drop in hours worked is heavily skewed towards market services, though the magnitude of this bias is not quite as large as in the data. In the data the ratio $H_{S} / H_{I}$ is equal to 5.12 in the US and 3.38 in Europe. The model predicts values of 3.91 and 4.31 for $\tau=.60$ and $\tau=.55$ respectively. When $\tau=.6$ the model implies the same time devoted to market services as in the data, but implies less time devoted to industry than in the data. When $\tau=.55$ the model implies more time devoted to market services and less time devoted to industry than is found in the data. While the model does not imply that taxes can account for all of the differences in market time allocations for this profile of technology, it does imply that taxes can account for the bulk of the observed differences between the US and Europe in 2000. 
Next we turn to the results for Case 2. While there is no presumption that taxes and technology alone can account for all of the differences in time allocations, it is of interest to ask what technology parameters would perfectly replicate the market time allocations for a given tax rate. The results look somewhat different for the two tax rates. For the case of $\tau=.60$ a large gap in industry and market services relative to the US is required to account for the European time allocation, whereas when $\tau=.55$ a large gap between home and market service productivity relative to the US is required. (Recall that the sign of the productivity difference is not really determined if one considers the two different forms of technological progress in the home sector.) The differences are intuitive given the results for Case 1. In Case 1, both tax rates generated too little time devoted to industry. The way to fix this is to make industry less productive relative to services. Since the gap is larger for $\tau=.60$, a larger productivity gap is required. Having fixed this dimension, it remains to get the right time allocated to market services. There are two mechanisms in the model that reallocate time between market services and the home sector: relative productivities and taxes. The larger the tax rate differences, for given preference parameters the greater will be the decrease in market services that is accounted for by taxes and the less need there is for relative productivity differences to contribute. If taxes decrease then more work must be done by the relative productivity channel.

\subsection{Taxes, Time Allocations and Welfare}

A closely related exercise to that carried out in the last subsection is to ask what time allocations in the US in 2000 would look like if tax and spending programs in the US were to be raised to European levels. Table 8 shows the results.

\begin{tabular}{|c|c|c|c|c|c|}
\hline \multicolumn{7}{|c|}{ Table 8} \\
\hline & Daxes and the 2000 US Time Allocation \\
\hline & US & Europe & $\tau=.40$ & $\tau=.55$ & $\tau=.60$ \\
\hline & .357 & .238 & .357 & .263 & .229 \\
\hline$H_{M}$ & .008 & .010 & .008 & .008 & .008 \\
\hline$H_{A}$ & .057 & .052 & .057 & .048 & .045 \\
\hline$H_{I}$ & .292 & .176 & .292 & .207 & .177 \\
\hline$H_{S}$ & & & .187 & .252 & .278 \\
\hline$H_{N}$ & & & .456 & .485 & .492 \\
\hline $1-H_{M}-H_{N}$ & & & &
\end{tabular}

The result is clear: if the US were to adopt European magnitude tax and spending programs, then the time allocation in the US would look remarkably similar to the time allocation in Europe. I conclude on the basis of this and the results from the previous subsection that tax differences seem to account for the bulk of the differences found in 2000 . 
This table also includes values for time spent in homework and leisure. In moving from $\tau=.40$ to $\tau=.60$ the table shows that market work decreases, home work increases and leisure increases. Much of the decrease in market work is offset by an increase in home work. Specifically, the total decrease in market work is .128, but there is an increase in home work of .091, implying that roughly $75 \%$ of the decrease in market work is offset by increased work at home. This magnitude is intermediate between the estimates of Ragan (2005) and those of Freeman and Schettkat (2002) and Olovsson (2004). This calculation underscores a key point. In this model, the dominant effect of taxes is to move work out of the market sector and into the home sector. While higher taxes do lead to a significant increase in leisure, the increase in leisure accounts for only about one quarter of the change in hours of market work.

It is worth commenting on the relationship between these results and those of Prescott (2004). Like Prescott, I have assumed preferences over consumption and leisure that are log-log. However, my model has added home production and assumed that time allocation between the home and market is quite elastic. In view of this one may wonder why I do not find even larger effects of taxes than Prescott. The reason is that both models assume that same fraction of the total time endowment is devoted to market work, implying that the model with home production has a lower value of leisure. Given identical log-log preferences in the two models, the percentage change in leisure in response to tax rates is very similar in the two models. But since leisure is lower in the home production, a given percentage change in leisure translates into a smaller change in time spent working. However, this smaller effect is then augmented by the effect associated with substitution between market and home production.

Finally, it is also of interest to assess the welfare effects of taxes in this model. In the context of the previous calculation for the US economy we ask by what amount the profile of nonagricultural market consumption would have to be decreased in order to make individuals indifferent to living in the economy with a tax rate of $60 \%$ as opposed to remaining in the economy with a tax rate of $40 \%$. The answer is $19 \%$, which is the same as that reported by Prescott (2004) for a similar calculation. This too may seem somewhat surprising given the presence of home production in the current analysis. While this makes hours of market work more responsive to taxes, it should also make the responses less costly from a welfare perspective since home production is a good substitute for market consumption. However, it should be noted that since the current analysis has no capital, the calculated welfare cost is probably more comparable to the steady-state welfare gain in the model of Prescott, which would be larger.

To summarize, this section shows that if the US in 2000 were to adopt European level tax and spending programs, time allocations in the US would change dramatically and would closely resemble those observed in Europe. Additionally, this would entail a large loss in welfare. 


\section{Conclusion}

This paper makes three key points regarding the evolution of labor market outcomes in Europe relative to the US. First, it argues that much of the literature on the European labor market problem has misdiagnosed the problem by focusing on relative unemployment rather than relative employment levels. Specifically, the magnitude of the problem is much larger than suggested by unemployment rate differentials and the timing is very different. Second, the key to the understanding the source of the European labor market problem is to understand why Europe has not developed a market service sector more similar to that of the US as it has closed the gap with the US in terms of output per hour. Third, it shows that a story in which productivity differences and taxes are central can potentially go a long way to accounting for the relative deterioration of European labor market outcomes. To be sure, the model analyzed here is very simple and the calculations must be viewed as a first step toward assessing the role of various factors in accounting for the evolution of hours worked across countries. An important task for

future work is to assess specific tax and spending programs in models that incorporate the heterogeneity that is relevant for these programs. 


\section{References}

[1] Aguiar, M., and E. Hurst, "Life Cycle Prices and Consumption," Mimeo, University of Chicago, 2005a.

[2] Aguiar, M., and E. Hurst, "Measuring Leisure: Evidence from Five Decades of Time Use Surveys," mimeo, University of Chicago, $2005 \mathrm{~b}$.

[3] Alesina, A., E. Glaeser, and B. Sacerdote, "Work and Leisure in the US: Why So Different?," mimeo, 2005, forthcoming in NBER Macroeconomics Annual.

[4] Baumol, W., "Macroeconomics of Unbalanced Growth: Anatomy of an Urban Crisis," American Economic Review 57: 415-426.

[5] Bernard, A., and C. Jones, "Comparing Apples to Oranges: Productivity Convergence and Measurement Across Industries and Space," American Economic Review 86 (1996), 1216-1238.

[6] Bertola, G., and A. Ichino, "Wage Inequality and Unemployment: United States vs. Europe" NBER Macro Annual, 1995, 13-53.

[7] Bertrand, M., and F. Kramarz, "Does Entry Regulation Hinder Job Creation? Evidence from the French Retail Industry," Quarterly Review of Economics 117 (2002), 1369-1413.

[8] Blanchard, O., and J. Wolfers, "The Role of Shocks and Institutions in the Rise of European Unemployment: The Aggregate Evidence", Economic Journal 110 (2000), 1-33.

[9] Chang, Y., and F. Schorfheide, "Labor Supply Shifts and Economic Fluctuations," Journal of Monetary Economics 50 (2003), 1751-1768.

[10] Daveri, F., and G. Tabellini, "Unemployment, Growth and Taxation in Industrial Countries", Economic Policy 15 (2000), 47-104.

[11] Davis, S., and M. Henrekson, "Tax Effects on Work Activity, Industry Mix and Shadow Economy Size: Evidence from Rich Country Comparisons", NBER Working Paper \#10509, 2004.

[12] Den Haan, W., "Temporary Shocks and Unavoidable Transitions to a HighUnemployment Regime", mimeo, 2003.

[13] Den Haan, W., C. Haefke, and G. Ramey, "Shocks and Institutions in a JobMatching Model", NBER Working Paper, 2002. 
[14] Echevarria, M., "Changes in Sectoral Composition Associated With Growth", International Economic Review 38 (1997), 431-452.

[15] Fonseca, R., P. Lopez-Garcia, and C. Pissarides, "Entrepreneurship, Start-Up Costs and Employment," European Economic Review 45 (2001), 692-705.

[16] Freeman, R., and R. Schettkat, "Marketization of Production and the US-Europe Employment Gap", NBER Working Paper, 2002.

[17] Gollin, D., S. Parente, and R. Rogerson, "The Food Problem and the Evolution of International Income Levels,", mimeo, 2005.

[18] Greenwood, J., A. Seshadri, and M. Yorokoglu, "Engines of Liberation," Review of Economic Studies 72 (2005), 109-133.

[19] Kongsamut, P., S. Rebelo, and D. Xie, "Beyond Balanced Growth", Review of Economic Studies 2001.

[20] Ljungqvist L., and T. Sargent, "The European Unemployment Dilemma," Journal of Political Economy 106 (1998), 514-550.

[21] Lucas, R.E., and L. Rapping, "Intertemporal Substitution of Leisure in the Theory of Labor Supply," Journal of Political Economy 77 (1969), 721-754.

[22] Maddison, A., Monitoring the World Economy, OECD, Paris, 1995.

[23] McGrattan, E., R. Rogerson, and R. Wright, "An Equilibrium Model of the Business Cycle with Household Production and Fiscal Policy," International Economic Review 38 (1997), 267-290.

[24] Mendoza, E., A. Razin, and L. Tesar, "Effective Tax Rates in Macroeconomics: Cross-Country Estimates of Tax Rates on Factor Incomes and Consumption," Journal of Monetary Economics 34 (1994), 297-323.

[25] Messina, J., "The Role of Product Market Regulations in the Process of Structural Change,", mimeo, European Central Bank, 2003.

[26] Mortensen, D. and C. Pissarides, "Unemployment Responses to Skill-Biased Technology Shocks," Economic Journal 109 (1999a) 242-265. ,"Job Reallocation and Employment Fluctuations," in eds., John Taylor and Michael Woodford, Handbook of Macroeconomics, Volume 1 pages 1171-1227, Amsterdam, Elsevier Press, 1999b

[28] Ngai, R., and C. Pissarides, "Structural Change in a Multi-Sector Model of Growth,", mimeo, London School of Economics, 2004. 
[29] Olovsson, C., "Why Do Europeans Work So Little?," mimeo, Stockholm School of Economics, 2004.

[30] Owens, John, Working Lives: The American Workforce Since 1920,Lexington Books, Lexington Ma, 1986.

[31] Prescott, E., "Why Do Americans Work So Much More than Europeans?", Quarterly Review of the Federal Reserve Bank of Minneapolis, July 2004, 2-13.

[32] Ragan, K., "Fiscal Policy and the Family: Explaining Labor Supply in a Model with Household Production," mimeo, University of Chicago, 2005.

[33] Rogerson, R., "Two Views on the Deterioration of European Labor Market Outcomes", Journal of the European Economic Association 2 (2004), (Papers and Proceedings) 447-455.

[34] Rupert, P., R. Rogerson, and R. Wright, "Estimating Substitution Elasticities in Household Production Models," Economic Theory 6 (1995), 179-193.

[35] Sorensen, A., "Comparing Apples to Oranges: Productivity Convergence and Measurement across Industries and Countries: Comment," American Economic Review 91 (2001), 1160-1167. 